HÉRAULT (Laurence), La Grande communion. Transformation et actualité d'une cérémonie catholique en Vendée

Paris, Éditions du C.T.H.S., 1996, 152 p.

François-André Isambert

\title{
OpenEdition
}

Journals

Édition électronique

URL : http://journals.openedition.org/assr/20768

DOI : $10.4000 /$ assr.20768

ISSN : $1777-5825$

Éditeur

Éditions de l'EHESS

Édition imprimée

Date de publication : 1 juin 2001

Pagination : 84-85

ISBN : 2-222-96704-X

ISSN : 0335-5985

Référence électronique

François-André Isambert, « HÉRAULT (Laurence), La Grande communion. Transformation et actualité d'une cérémonie catholique en Vendée », Archives de sciences sociales des religions [En ligne], 114 | avriljuin 2001, document 114.16, mis en ligne le 19 août 2009, consulté le 21 septembre 2020. URL :

http://journals.openedition.org/assr/20768 ; DOI : https://doi.org/10.4000/assr.20768

Ce document a été généré automatiquement le 21 septembre 2020.

(C) Archives de sciences sociales des religions 


\section{HÉRAULT (Laurence), La Grande communion. Transformation et actualité d'une cérémonie catholique en Vendée}

Paris, Éditions du C.T.H.S., 1996, 152 p.

François-André Isambert

\section{RÉFÉRENCE}

HÉRAULT (Laurence), La Grande communion. Transformation et actualité d'une cérémonie catholique en Vendée, Paris, Éditions du C.T.H.S., 1996, 152 p.

1 Ce petit livre, très dense, y compris au point de vue de la typographie, est exemplaire. Au début, on est étonné de lire: «Parmi les rites de passage du domaine français, la communion solennelle est l'un de ceux qui a été le moins étudié » (p. 7). Un coup d'oeil à la bibliographie montre que l'auteur connait fort bien les « travaux sociologiques à ce sujet, mais l'angle ethnologique dans lequel elle se place est bien moins pourvu, les ethnologues ayant privilégié l'aspect «folklorique » d'un cérémonial assez pauvre sur ce terrain. Il s'agit, pour elle, d'étudier les rites sous leur aspect proprement religieux, un peu comme l'avait fait Yves Lambert dans son Dieu change en Bretagne. Un point de vue résolument descriptif est sous-tendu par une méthodologie et une conceptualisation spécifiquement ethnographiques. La composition et l'ordre des séquences rituelles prennent le pas sur les idées qui président à leurs transformations. Aussi, se référant aux travaux de Serge Bonnet et de moi-même, et aux débats qu'ils prenaient comme objet, elle décide: «Bien que ce débat ait accompagné la transformation du cérémonial de la communion, je n'ai pas voulu lui accorder ici une place centrale. Il m'a semblé plus intéressant d'analyser les modifications concrètes et diverses de la cérémonie dans les paroisses du doyenné (celui de Morton dans le Haut- 
Bocage vendéen) de manière à en saisir le cheminement et les principales caractéristiques» (p.52). Effectivement, ce qui manque le plus aux travaux sociologiques dont il est question, c'est l'observation de terrain, au profit des évaluations macrosociologiques. Le reproche qu'on peut adresser à l'A. c'est de trouver celles-ci peu intéressantes. Mais elle nous fait toucher du doigt tout l'intérêt que représente une analyse microsociale des changements dans les pratiques, ce qui passionnait au plus haut point Gabriel Le Bras (que l'A. ne cite qu'une fois dans sa bibliographie, pour L'Église et le village). Un avantage immédiat de cette manière de faire est de désidéologiser complètement l'analyse et de garantir l'objectivité.

2 Mais les faits sont têtus et l'A. retrouve dans la succession des phases de l'histoire quelque chose du dynamisme qui animait les réformes, avec, en plus, l'économie de ce pari que pouvait être le fait d'assimiler au passé (révolu) et à l'avenir (qui arrivera) respectivement les solutions traditionalistes et progressistes. Or, de fait, trois périodes apparaissent depuis le début du XXe siècle jusqu'aux années quatre-vingt-dix : celle de la "communion solennelle», en gros jusqu'en 1940, puis celle des tensions entre " communion solennelle» et "profession de foi », autour des années soixante, enfin celle des « fêtes de la foi ».

Chacune de ces périodes comporte des traces de la précédente et une polarité entre nostalgiques et réformistes. Il en résulte une typologie que l'A. a voulu commandée moins par des oppositions idéologiques que par une multiplicité de causes débouchant sur une plus ou moins grande richesse rituelle. Mais celle-ci fait complètement éclater, à cette échelle, les corrélations que l'on croyait bien établies avec l'avancée du phénomène urbain ou le niveau de la pratique dominicale.

Dès la première phase, les paroisses à rites nombreux et obligatoires (les rites religieux l'emportant en nombre sur les rites profanes, mais n'excluant pas ceux-ci) s'échelonnent autour de communautés plus discrètes où des rites secondaires comme la consécration à la Vierge font parfois défaut. Le profane est ici comme enveloppé par le religieux et est cité à ce titre. Le terme de "profession de foi " se développe à un moment où le sens d'une communion qui n'est plus la première, semble pouvoir être apporté par un de ses rites composants, le «renouvellement des promesses du baptême ». C'est le lieu de s'interroger sur le fait que l'A. ne fait pas mention de la confirmation qui, dans bien des diocèses, fait partie de la séquence rituelle et même, dans certains cas, prend le pas sur la communion. Mais le secteur d'observation est ici limité et la mise hors séquence de la confirmation est sans doute un fait local sur lequel l'A. pense ne plus avoir à revenir. Il y a néanmoins des absences qui demandent à être expliquées. La chose aurait été d'autant plus désirable que, précisément, cette seconde période est caractérisée par la discussion et la recherche et que la "profession de foi » n'apparaît que comme une des solutions pour combler le vide laissé par la communion solennelle. Ainsi se prépare progressivement le terrain vers les "fêtes de la foi", résultats d'une décision diocésaine. L'aboutissement est à la fois le raccordement des deux «communions" et l'échelonnement de la fête à la fin des quatre années de catéchisme (désormais appelées du nom des années scolaires correspondantes: CE1. CE2, CM1, CM2). À travers cette succession, les anciennes fêtes transparaissent et gardent parfois leur nom.

5 Les « fêtes de la foi » occupent à elles seules près de la moitié du livre. Elles présentent une assez grande diversité, dont l'A. rend compte, paroisse après paroisse, tout en résumant le dessin de leur typologie, ordonnée entre un «modèle maximal» et un 
«modèle minimal ». Cette polarisation ne caractérise pas une plus ou moins grande conformité à la tradition (contrairement au cas de la " communion solennelle») parce que la « liturgie de la parole » est celle où s'épanchent le plus les courants novateurs et en même temps celle dont on fait le plus d'économie dans la version minimale. Dans l'ensemble, le rituel religieux a perdu (ou s'est débarrassé de) tout ce qui pouvait dénoter un "rite de passage » au sens de Van Gennep. Inversement, le rituel profane semble avoir récupéré au moyen de repas, souvent au restaurant, et de cadeaux très fréquemment utilitaires comme une montre ou une bicyclette, la fonction d'assurer la transition de l'enfance à l'adolescence.

6 Cette analyse fournit un véritable lexique pour la lecture de la «diversité des formes liturgiques contemporaines », en appuyant sur la non-incompatibilité des deux termes «diversité » et «liturgiques». C'est en effet que, parmi les diverses clés de cette diversité, il y a les acteurs, qui ne sont plus seulement les prêtres, mais aussi les communiants et leurs parents, dont le rôle est renforcé au cours de séances de préparation dans lesquelles chacun dit son mot. Ainsi, le rite tel qu'il est accompli apparaît comme un ensemble de variations autour d'un texte officiel, variations gérées à la fois par les participants et par l'institution qui en donne le schéma. 